\title{
QUEEN'S
UNIVERSITY
BELFAST
}

\section{Pulsed light reduces the toxicity of the algal toxin okadaic acid to freshwater crustacean Daphnia pulex}

Murray, I. M. T., Rowan, N. J., McNamee, S., Campbell, K., \& Fogarty, A. M. (2017). Pulsed light reduces the toxicity of the algal toxin okadaic acid to freshwater crustacean Daphnia pulex. Environmental Science and Pollution Research, 1-8. https://doi.org/10.1007/s11356-017-0472-6

Published in:

Environmental Science and Pollution Research

Document Version:

Peer reviewed version

Queen's University Belfast - Research Portal:

Link to publication record in Queen's University Belfast Research Portal

Publisher rights

(c) 2017 Springer International Publishing AG. This work is made available online in accordance with the publisher's policies. Please refer to any applicable terms of use of the publisher.

\section{General rights}

Copyright for the publications made accessible via the Queen's University Belfast Research Portal is retained by the author(s) and / or other copyright owners and it is a condition of accessing these publications that users recognise and abide by the legal requirements associated with these rights.

Take down policy

The Research Portal is Queen's institutional repository that provides access to Queen's research output. Every effort has been made to ensure that content in the Research Portal does not infringe any person's rights, or applicable UK laws. If you discover content in the Research Portal that you believe breaches copyright or violates any law, please contact openaccess@qub.ac.uk. 


\title{
Pulsed-light reduces the toxicity of the algal toxin okadaic acid to freshwater crustacean Daphnia pulex
}

Iain MT Murray ${ }^{1^{*}}$, Neil J Rowan ${ }^{1,2}$, Sara McNamee ${ }^{3}$, Katrina Campbell ${ }^{3}$, Andrew M Fogarty ${ }^{1,2}$

* Corresponding Author Tel: +353 892068104; email: imurray@ait.ie

${ }^{1}$ Department of Life \& Physical Science, Athlone Institute of Technology, Dublin Road, Athlone, Co. Westmeath, Ireland.

2 Bioscience Research Institute, Athlone Institute of Technology, Dublin Road, Athlone, Co. Westmeath, Ireland.

${ }^{3}$ Institute for Global Food Security, School of Biological Sciences, Queen's University, Belfast, Co. Antrim, Northern Ireland.

\section{Acknowledgements}

The component of research conducted at Queen's University was funded by the Advanced ASSET project, partly funded through InvestNI and from the European Sustainable Programme 2007-2013 under the European Regional Development Fund (“ERDF”).

The component carried out in Athlone Institute of Technology was funded by the Institute's Department of Life and Physical Sciences with thanks to Head of Department Dr. Carol O' Donnell, and Dean of Faculty of Science Dr. Don Faller.

\begin{abstract}
This constitutes the first study to report on the reduction in toxicity of the dinoflagellate algal toxin okadaic acid after novel pulsed light (PL) treatments where ecotoxicological assessment was performed using a miniaturised format of the conventional in vivo freshwater crustacean Daphnia sp. Acute toxicity test. Bivalves accumulate this toxin, which can then enter the human food chain causing deleterious health effects such as Diarrheic Shellfish Poisoning. This miniaturised toxicological bioassay used substantially less sample volume and chemical reagents. Findings revealed a $24 \mathrm{~h} \mathrm{EC_{50 }}$ of $25.87 \mu \mathrm{g} / \mathrm{L}$ for PL-treated okadaic acid at UV dose of $12.98 \mu \mathrm{J} / \mathrm{cm}^{2}$ compared to a $24 \mathrm{~h} \mathrm{EC}_{50}$ of $1.68 \mu \mathrm{g} / \mathrm{L}$ for the untreated okadaic acid control, suggesting a 15 -fold reduction in toxicity to Daphnia pulex. The bioassay was validated in this study and correlated well with the "classic" ISO format $(\mathrm{r}=$ $0.98)$ using the traditional reference chemical potassium dichromate $\left(\mathrm{K}_{2} \mathrm{Cr}_{2} \mathrm{O}_{7}\right)$. Reduction by up to $65 \%$ in PL-treated okadaic acid concentration was confirmed by LC-MS/MS analysis. Findings from this study have positive ecological, societal and enterprise implications, such as the development of PL technology for the prevention or reduce algal contamination of fisheries and aquaculture industries.
\end{abstract}

\section{Keywords}

Pulsed-light, Harmful algal blooms, Okadaic acid, Diarrhetic shellfish poisoning, Daphnia pulex, Ecotoxicology, Detoxification. 


\section{Introduction}

Toxic algal blooms are problematic in Ireland and globally. Algal species that produce toxins include Karenia mikimotoi, Microcystis aeruginosa, Dinophysis spp. and Alexandrium spp. In the summer of 2012, the Irish Oyster Industry was devasted by toxic blooms of Karenia mikimotoi, and in October 2016, the Irish Marine Institutes Weekly Harmful Algal Bloom Bulletin (9- 15 October 2016), reported that up to $11 \%$ of Irish Aquaculture sites were affected with toxic levels of DSP from Dinophysis spp. The Irish Fisheries Board (Bord Iascaigh Mhara 2015) suggest that Irish aquaculture industries were worth an estimated $€ 115$ million to the economy in 2014. As most of the aquaculture industry is located in estuarine waters it is susceptible to upstream municipal or agricultural pollution leading to eutrophication. The economic importance is evident as failures or closures of these industries can have an economically devastating effect on communities dependant on aquaculture. The closures of bivalve fisheries off the west coast of Ireland are frequent due to the presence of Diarrheic Shellfish Poisoning (DSP) causing Dinophysis spp. algal blooms and Azaspiracid Poisoning (AZP) in the blue edible mussel Mytilus edilus. First reported in 1995, AZP was associated with ingestion of contaminated shellfish from Killary Harbour (Ireland) and has been subsequently implicated in several food poisoning incidents (Twiner et al. ,2008) although the symptoms were typical of DSP, the levels of DSP toxins in these Irish shellfish were well below regulatory levels. Consumption of shellfish contaminated with DSP toxins from Dinophysis spp., can lead to DSP (Kumagai et al, 1986). DSP toxins include Okadaic Acid (OA) and its derivatives (dinophysistoxins DTX-1 and DTX-3) belong to the lipophilic toxins group (Ben-Gigirey et al., 2007; Luppis et al., 2011). DSP symptoms include diarrhoea, nausea, vomiting and abdominal pain which can appear from $30 \mathrm{~min}$ to a few hours after ingestion with complete recovery occurring after several days (Yasumoto et al., 1978).

Thus far, the only means of managing marine biotoxin episodes is exclusion from the food chain by means of monitoring programs (Luppis et al., 2011). Appropriate development of shellfish detoxification approaches would be desirable. Such methods should be rapid, efficient, easy-to-apply and not alter the quality of sensory properties of shellfish. Albeit very limited, methods investigated so far for this purpose include thermal processing, freezing, evisceration, supercritical $\mathrm{CO}_{2}$ with acetic acid, $\gamma$-irradiation and ozonation ( FAO, 2016; Lupiss et al., 2011). Of these aforementioned interventions, only ozonation resulted in effective toxin reduction (in the range of 6-100\%, 25-83\% and $21-66 \%$ for free OA, OA esters and total OA respectively). Luppiss et al., (2011) reported that reduction of OA content was substantially higher in homogenised $\mathrm{O}_{3}$ - treated mussel tissue compared with whole shucked mussels. The appearance and texture of $\gamma$-irradiated mussels deteriorated pointing to low potential for commercial use.

There are a number of existing protocols for the measurement of $\mathrm{OA}$ which must be maintained at levels below $160 \mu \mathrm{g} / \mathrm{kg}$ of edible material from live bivalve molluscs as set out in Chapter V (2) of Section VII of Annex III to Regulation (EC) No 853/2004 as amended by (EU) 786/2013, (Food Safety Authority of Ireland, 2015). Annex III of Regulation (EC) 2074/2005 sets out the analytical methods to be used by competent authorities to check compliance with the above named legislations prescribed limits. Analytical methods were reviewed by Prego-Faraldo, et al, (2013) and include both biological and chemical methods. The most widely used and accepted methods are the Mouse BioAssay (MBA) and liquid chromatography. Biochemical methods such as the PP2A inhibition assay and immunological methods are also becoming popular. Chemical methods are usually High Performance Liquid 
Chromatography (HPLC) coupled with detection systems such as Mass Spectrometry (LC-MS) or Ultra Violet Detection. In terms of biological assessments, the MBA is most widely accepted and is prescribed under EU Regulation 2074. However, with the associated costs and ethical issues surrounding mammalian test systems, there is a trend towards alternative test systems such as crustacean bioassays. Prego-Faraldo et al., (2013) reports that Daphnia magna bioassay lacks sensitivity and cannot completely replace the MBA, although it is inexpensive and capable of measuring Okadaic acid levels tenfold lower than the lower limit of detection of the MBA. This is supported by the findings of Vernoux et al., (1993), who assessed toxicity of OA from mussel extracts to Daphnia magna with comparisons to MBA and HPLC methods and reports an $\mathrm{EC}_{50}$ of $15 \pm 1.8 \mu \mathrm{g} / \mathrm{L}$ for the Daphnia magna bioassay and $85 \%$ correlation with HPLC methods. In the last decade substantive efforts focused on the development of alternative analytical tools to the accredited AOAC mouse bioassay of Yasumoto et al., (1978) for okadaic acid detection. The enhancements in LC-MS/MS technology in this time and the provision of analytical standards enabled researchers to develop and validate methods for regulatory analysis (Fux et al. 2009, 2011; Gerssen et al. 2011). Commission Regulation Number 15/2011 states that the liquid chromatography-mass spectrometric (LC-MS/MS) method should now be applied as the reference method for the measurement of marine lipophilic toxins in shellfish including OA. The implementation of LC-MS/MS allowed the phasing out of the live animal assay in EU Member States and since 31 December 2014 as the standard reference method applied to the regulatory monitoring of OA and other lipophilic toxins in shellfish. For regulatory laboratories the LC-MS/MS method is fit-for-purpose for known regulated toxins though requires expensive high specification equipment, trained personnel for its operation and analytical standards.

The freshwater crustacean Daphnia magna has been widely used and validated as an ecotoxicological assessment tool for decades (Vernoux et al., 1993; Prego-Faraldo et al., 2013). The test has been accredited as an ISO test (ISO 6341:2012) and an OECD test (OECD 202 : 2004).

As stated in OECD 202 adopted in April 2004: Guidelines for Testing of Chemicals: Daphnia sp., Acute Immobilisation Test states that Daphnia magna Straus is the preferred test species although other suitable Daphnia species can be used for example Daphnia pulex (OECD 202: 2004). Lilius et al., (2005) also reported no significant difference between Daphnia magna and Daphnia pulex in a selection of 30 different test chemicals. Adaptations of this assay have been reported by Baumann et al., (2014) for the purposes of testing nanomaterials however the miniaturisation performed in this study further reduced test volumes to 5 organisms $/ 2.5 \mathrm{~mL}$ test volume well across four replicate wells. Testing 20 organisms in 4 wells with a total test volume requirement of $10 \mathrm{~mL}$ maintained the $5 \%$ significance level of one immobile daphnid, but further reduced the test material requirements to $25 \%$ of the classic glass test.

Pulsed light (PL) technology has received considerable attention as a promising next-generation energyefficient approach for decontaminating food, packaging and air (Hayes et al., 2013: Garvey et al., 2016; Rowan et al., 2016). This approach kills microorganisms using ultrashort duration pulses of an intense broadband emission spectrum that is rich in UV-C germicidal light (200-280 nm). PL is produced using techniques that multiply power manifold by storing electrical energy in a capacitor over relatively long times (fraction of a second) and releasing it in a short time (millionths or thousands of a second) using sophisticated pulse compression techniques (Rowan et al., 2016). A strong advantage of using pulsed xenon lamps over continuous low to medium pressure conventional UV lamps is that the former has a peak power dissipation, which allows for more microbial inactivation due to greater intensity of the light pulses. Despite significant interest in the development of PL as an alternative or complementary means of disinfection, published studies to date have focused on microbial pathogens including bacteria (Garvey et al., 2016; Rowan et al., 2016), yeast (Farrell et al., 2011), fungi (Rowan, 2011), parasites 
(Garvey et al., 2010; Garvey et al., 2014), and viruses (Rowan et al., 2016) for food and water applications. To date, there has been no study on the potential of PL to reduce the toxicity of algal toxins. Therefore, the objective of this timely study was to investigate efficacy of pulsed light as an 'environmentally-friendly' decontamination technology for novel reduction or removal of the algal toxin okadaic acid (OA) in water, and to ascertain the ecotoxicological status of PL-treated OA using a modified version of the Daphnia assay.

\section{Materials and Methods}

Daphnia pulex culture: Laboratory stocks of Daphnia pulex were cultured in accordance with ISO6341: 2012. Culturing was carried out in $2 \mathrm{~L}$ glass beakers in a Phytoincubator @ $20^{\circ} \mathrm{C} \pm 1^{\circ} \mathrm{C}$ on 16:8 hr light: dark cycle at 4000 lux in Elendt M4 media and fed fresh Pseudokirchneriella subcapitata algae.

Acute toxicity testing: Dilution media was prepared in accordance with ISO 6341: 2012 by dissolving $11.76 \mathrm{~g}, 4.93 \mathrm{~g}, 2.59 \mathrm{~g}$ and $0.23 \mathrm{~g}$ of $\mathrm{CaCl}_{2} .2 \mathrm{H}_{2} 0, \mathrm{MgSO}_{4} .7 \mathrm{H} 2 \mathrm{O}, \mathrm{NaHCO}_{3}$ and $\mathrm{KCl}$ (Sigma Aldrich) respectively in $1 \mathrm{~L}$ of distilled deionized water $\left(\mathrm{dd} . \mathrm{H}_{2} \mathrm{O}\right) .125 \mathrm{~mL}$ of each component was then mixed well to $5 \mathrm{~L}$ dd. $\mathrm{H}_{2} \mathrm{O}$ and aerated with a standard aquarium air pump and air stone for 1 hour. Standard volume $(10 \mathrm{~mL})$ tests were carried out in accordance with ISO 6341: 2012. Final concentrations tested were 0.0, 0.1, 0.5, 1.0, 1.5, 2.0, 2.5, $5.0 \mathrm{mg} / \mathrm{L} \mathrm{K}_{2} \mathrm{Cr}_{2} \mathrm{O}_{7}$ Reference Chemical (Sigma-Aldrich, Product No. 207802, CAS No. 7778-50-9).

Adapted (Miniaturised) format OA acute toxicity test: Gravid females were isolated from lab stock cultures into small groups in $8.5 \mathrm{~cm}$ petri dishes prior to hatching. Once hatched, five age synchronised neonates $<24 \mathrm{hrs}$ old were removed in $2 \mathrm{~mL}$ culture medium for $0.00-50 \mu \mathrm{g} / \mathrm{L} \mathrm{OA}$ and $1.5 \mathrm{~mL}$ for $100 \mu \mathrm{g} / \mathrm{L} \mathrm{OA}$ (to allow for subsequent dilution) to each of four wells of a standard 24 well plate (Sarstedt ${ }^{\mathrm{TM}}$ ) giving a total of 20 daphnids per treatment.

From a working stock of $250 \mu \mathrm{g} / \mathrm{L}$ Okadaic acid ammonium salt from Prorocentrum concavum (SigmaAldrich, Product No. O8010, CAS No. 155716-06-6) final concentrations tested were 0.00, 0.01, 0.05, $1.00,5.00,10.0,25.0,50.0$ and $100 \mu \mathrm{g} / \mathrm{L}$. Test chemicals were initially made up to $5 \mathrm{X}$ required concentrations for $0.00-50 \mu \mathrm{g} / \mathrm{L}$ and $2.5 \mathrm{X}$ for $100 \mu \mathrm{g} / \mathrm{L}$. From this stock, $0.5 \mathrm{~mL}$ of each concentration $(0.00-50 \mu \mathrm{g} / \mathrm{L})$ and $1.0 \mathrm{~mL}$ for $100 \mu \mathrm{g} / \mathrm{L}$ were pipetted gently into each well as required to achieve a final $1 \mathrm{X}$ desired concentration. All dilutions were made in culture medium as described above. Immobilised Daphnia pulex were enumerated visually after 24 hours' exposure. For all tests, any daphnid that failed to mobilise within 15 seconds of gentle agitation with a glass rod was considered to be immobile.

Treatment of OA with PL: A portable pulsed power source (PUV-1, Samtech Ltd., Glasgow) was used to power a low-pressure $(60 \mathrm{kPa})$ xenon-filled flashlamp (Heraeus Noblelight XAP type NL4006 series constructed from a clear UV transparent quartz tube) that produced a high-intensity diverging beam of polychromatic pulsed light (as per Naughton et al. 2017). This irradiation system produces ultra-short duration pulses of an intense broadband emission. Pulsed light (PL) is produced by storing electricity in a capacitor over relatively long times and releasing it as a short duration pulse using sophisticated pulse compression techniques. The PL has a broadband emission spectrum extending from the UV to the infrared with a rich UV content, and its intensity also depends on the level of voltage applied. The light source has an automatic frequency control function which allows it to operate at 1 pulse per second (pps); this setting was used throughout the study. OA in each respective concentration was treated with PL at increasing fluences $\left(\mu \mathrm{J} / \mathrm{cm}^{2}\right)$ in $10 \mathrm{~mL}$ static volumes that were dispensed into sterile Petri dishes. Light exposure was homogenous as the xenon lamp measuring 9.75 $\mathrm{cm}$ was longer that the $8.5 \mathrm{~cm}$ standard diameter Petri dish used to treat the solutions. 
Quantification of test chemicals: Quantification of potassium dichromate was carried out by UV-Vis wavelength scan using a double beam instrument Cary Eclipse ${ }^{\mathrm{TM}}$. The scan was performed over the wavelengths $300-650 \mathrm{~nm}$. The magnitude of $\lambda \max _{2}$ peak of approximately $350 \mathrm{~nm}$ was used to quantify the samples relative to each other and a standard curve produced.

Two sample sets were analysed, clean and spent. Clean samples are samples of media taken prior to use in the test, i.e. pre-daphnid exposure $(0-250 \mu \mathrm{g} / \mathrm{L})$. Spent medium were taken after the test, i.e. post daphnid exposure $(0-100 \mu \mathrm{g} / \mathrm{L})$. For all samples, $(2.5 \mathrm{~mL}$ replicates $)$ were pooled into $10 \mathrm{~mL}$ samples and analysed for OA by LC-MS/MS using an Acquity UPLC system coupled to a Quattro premier XE mass spectrometer (Waters, Ireland). The method applied was a modification of the standard operating procedure used by the European Union Reference laboratory for marine biotoxins (EU-RL-MB, Version 5, 2015). Detection and quantification was achieved using targeted analysis via Multiple Reaction Monitoring (MRM) involving the fragmentation of specific precursor ion (parent) using argon as the collision gas, to at least 2 product ions (daughters). The system was operated in electrospray negative mode $\left(\mathrm{ESI}^{-}\right)$and the parameters were as follows: capillary voltage $2.8 \mathrm{kV}$, source temperature $120^{\circ} \mathrm{C}$, desolvation temperature $400^{\circ} \mathrm{C}$, desolvation gas flow $750 \mathrm{~L} / \mathrm{h}$. Chromatographic separation was achieved on an acquity UPLC BEH C18 column ( $100 \mathrm{~mm} \times 2.1 \mathrm{~mm}$ id, $1.7 \mu \mathrm{m}$ particle size $)$ at a column temperature of $45^{\circ} \mathrm{C}$ and flow rate of $0.4 \mathrm{ml} / \mathrm{min}$. Mobile phase A was $100 \%$ water and mobile phase B was $90 \%$ acetonitrile $/ 10 \%$ water (v/v) both containing $0.05 \%$ ammonia. A gradient from $20 \%$ to $55 \% \mathrm{~B}$ was run over $5 \mathrm{~min}$, held for $1 \mathrm{~min}$ followed by the resetting to initial composition and $2.5 \mathrm{~min}$ re-equilibration time. All separations occurred in negative mode. Calibration curves of OA were prepared from $3.125-200 \mathrm{ng} / \mathrm{ml}$ in clean and spent solutions using GraphPad Prism v6. Retention times of $3.51 \mathrm{~min}$ were observed following a slight shift from $3.69 \mathrm{~min}$. Transitions used for quantification for OA were $803.35>255.1$ and $803.35>112.9$. Samples were also analysed for DTX1 based on the transitions $817.4>255.0$ and $817.4>112.9$. However, no DTX1 was observed.

Statistical analysis of ecotoxicological responses: Statistical analysis using GraphPad Prism v6 was carried out to compare all ecotoxicological responses with respective controls. The initial statistical test employed was the Anderson-Darling test for normality. This test found that there was insufficient evidence to classify the data as being from a Gaussian distribution, and therefore the performance of non-parametric tests was suggested. ISO 6341:2012 refers to Gaussian distribution for statistical significance determination. The $\mathrm{K}_{2} \mathrm{Cr}_{2} \mathrm{O}_{7}$ results were analysed by both parametric and non-parametric tests. These included substitution of the paired t-test with its non-parametric counterpart, the MannWhitney U test, and substitution of the Dunnett's test with the non-parametric alternative the KruskalWallis test. Upon comparison of a data from the $\mathrm{K}_{2} \mathrm{Cr}_{2} \mathrm{O}_{7}$ Classic test in both parametric and nonparametric test suites, the resultant significance values, NOEC (No Observed Effect Concentration), LOEC (Lowest Observed Effect Concentration), MOEC (Maximum Observed Effect Concentration) and $\mathrm{EC}_{50}$ (Effective Median Concentration), were the same irrespective of the parametric strategy. Taking this into account, and given the tendency for other researchers to assume normal distribution and the reference in ISO 6341:2012 to Gaussian distribution, all further tests carried out were the parametric t-test and Dunnett's test and these were used to determine the NOEC and LOEC values on the assumption that additional replication would provide evidence of normality. Pearson Correlation was used to derive a correlation coefficient for the adapted method. 


\section{Results}

Untreated OA was found to be 15 fold more toxic to Daphnia pulex than PL treated OA. The $\mathrm{EC}_{50}$ for untreated OA was $1.68 \mu \mathrm{g} / \mathrm{L}(95 \% \mathrm{CI} 0.79-3.55 \mu \mathrm{g} / \mathrm{L})$ whilst the $\mathrm{EC}_{50}$ for PL treated OA was observed to be $25.87 \mu \mathrm{g} / \mathrm{L}(95 \% \mathrm{CI} 16.68-40.10 \mu \mathrm{g} / \mathrm{L})$ as shown in Fig 1 . A concomitant reduction in detected OA was also observed by LC-MS/MS following PL treatment. Figure 2 provides graphical data on the reduction in the detectable OA by LC-MS/MS following PL treatment. Nominal concentrations of 0.1 and $0.5 \mu \mathrm{g} / \mathrm{L}$ were both below the limit of detection post PL treatment and the maximal concentration of detected OA $100 \mu \mathrm{g} / \mathrm{L}$ was reduced by over $65 \%$ post PL treatment. No significant difference was

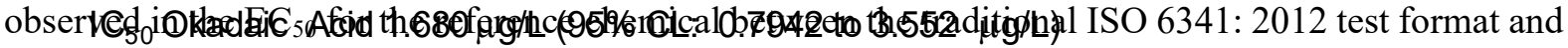

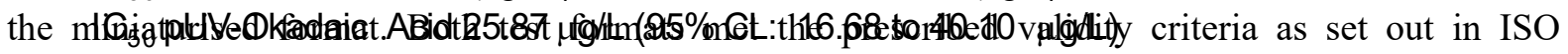
6341:2012, see Table 1. The test formats were correlated using Pearson Correlation. The Correlation Coefficient was 0.9883 (95\% CI $0.9334-0.9980)$ as shown in Fig 3 below.

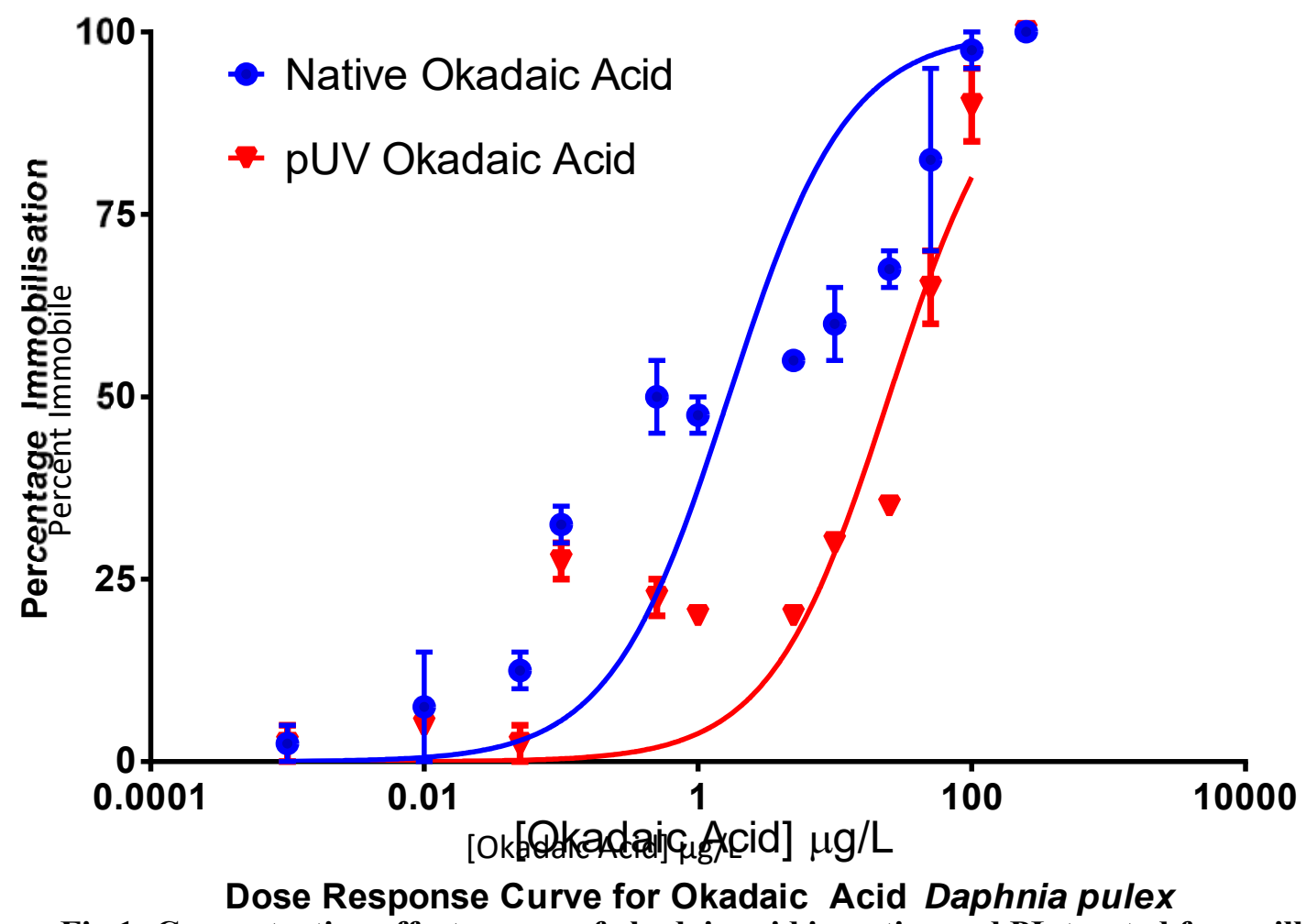

Fig 1: Concentration effect curves of okadaic acid in native and PL treated forms illustrating toxicity to Daphnia pulex over 24 hours. 


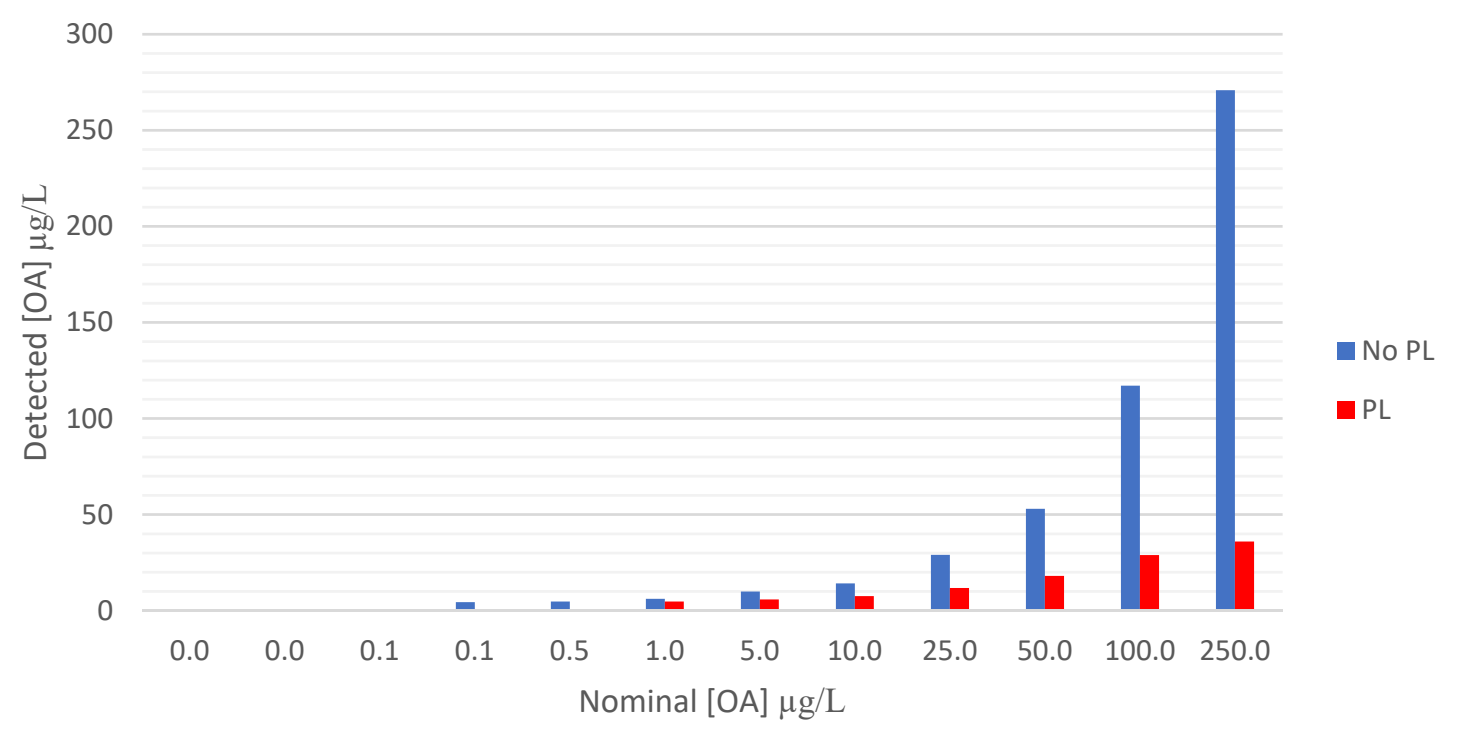

Fig 2: Comparison of okadaic acid nominal concentration with LC-MS/MS detected okadaic acid in native and PL treated forms from spent medium samples.

Table 1: Toxicity assessment of okadaic acid and PL treated OA demonstrating toxicity to Daphnia pulex over 24 hours.

\begin{tabular}{|l|l|l|}
\hline Attribute & Okadaic Acid & PL Treated Okadaic Acid \\
\hline EC $_{\mathbf{5 0}}$ & $1.68 \mu \mathrm{g} / \mathrm{L}(0.79-3.55 \mathrm{~g} / \mathrm{L})^{\mathrm{a}}$ & $25.87 \mu \mathrm{g} / \mathrm{L}(16.68-40.10 \mu \mathrm{g} / \mathrm{L})^{\mathrm{a}}$ \\
\hline NOEC & $0.05 \mu \mathrm{g} / \mathrm{L}$ & $0.05 \mu \mathrm{g} / \mathrm{L}$ \\
\hline LOEC & $0.10 \mu \mathrm{g} / \mathrm{L}$ & $1.00 \mu \mathrm{g} / \mathrm{L}$ \\
\hline MOEC & $100.00 \mu \mathrm{g} / \mathrm{L}$ & $100.00 \mu \mathrm{g} / \mathrm{L}$ \\
\hline
\end{tabular}

a. $95 \%$ Confidence Interval 


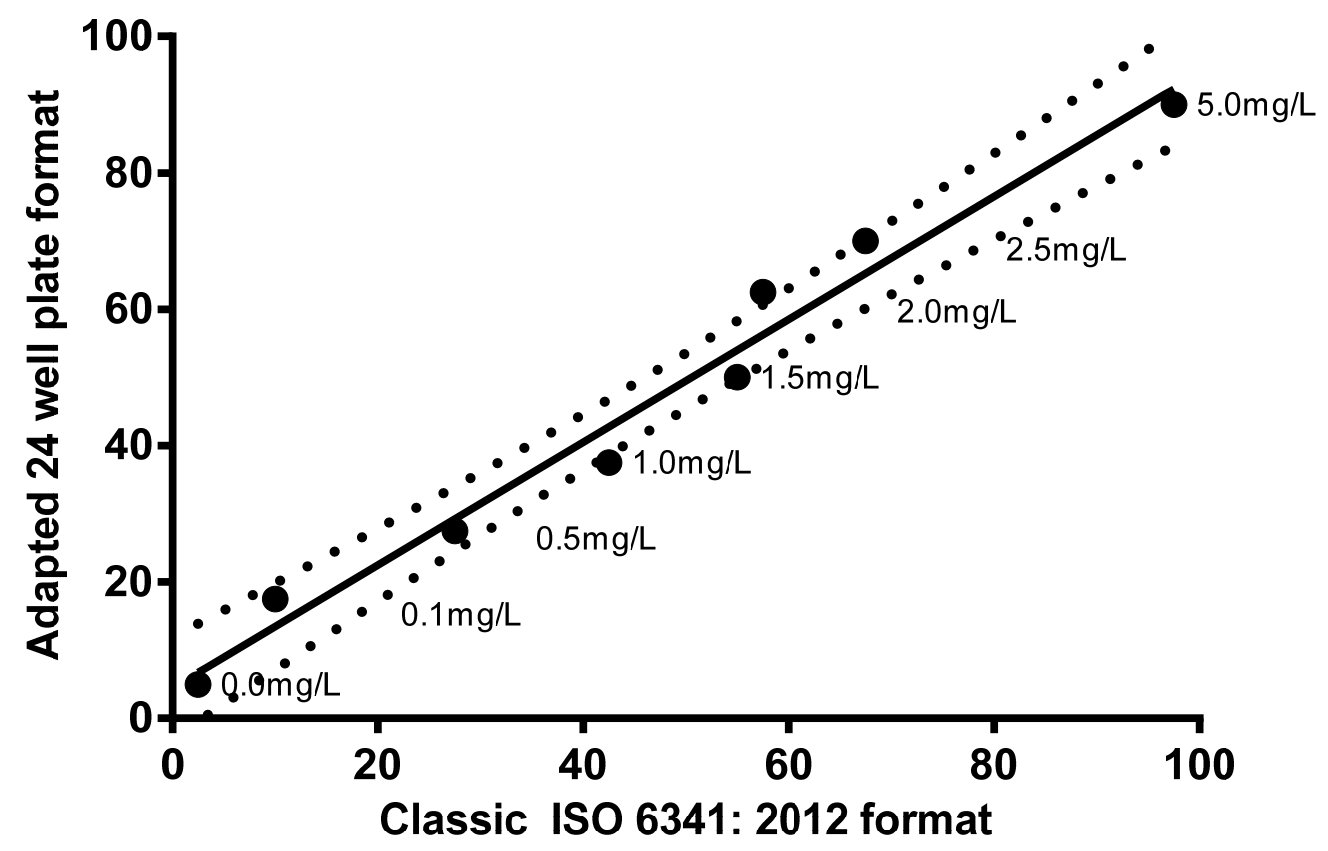

Fig 3: Correlation of miniaturised $24 \mathrm{hr}$ method with classic 24hr ISO method. Pearson Correlation Coefficient 0.9883 (95\% Confidence Interval 0.9344 - 0.9980 )

Table 2 below provides the percentage loss of OA detection by LC-MS/MS pre and post PL treatment. Figures 4 and 5 provide LC-MS/MS chromatograms of the $100 \mu \mathrm{g} / \mathrm{L}$ spent samples also pre and post PL treatment. Supplementary documentation accompanying this paper provide all chromatograms and raw data.

Table 2: Comparison of detected OA by LC-MS/MS pre and post PL treatment

\begin{tabular}{|c|c|c|c|}
\hline $\begin{array}{r}\text { Nominal } \\
\text { OA }[\mu \mathrm{g} / \mathrm{L}]\end{array}$ & $\begin{array}{r}\text { Average OA }[\mu \mathrm{g} / \mathrm{L}] \\
\text { untreated }\end{array}$ & $\begin{array}{r}\text { Average OA }[\mu \mathrm{g} / \mathrm{L}] \\
\text { PL treated }\end{array}$ & $\begin{array}{r}\% \text { drop following PL } \\
\text { treatment }\end{array}$ \\
\hline O & $\mathrm{ND}$ & ND & $\mathrm{ND}$ \\
\hline 0.01 & ND & ND & ND \\
\hline 0.05 & ND & ND & ND \\
\hline 0.1 & 4.45 & ND & ND \\
\hline 0.5 & 4.8 & ND & ND \\
\hline 1.0 & 6.2 & 4.75 & 33.39 \\
\hline 5.0 & 10 & 5.9 & 41.00 \\
\hline 10.0 & 14.25 & 7.6 & 46.67 \\
\hline 25 & 29.1 & 11.85 & 59.28 \\
\hline 50 & 53 & 18.05 & 65.94 \\
\hline 100 & 117.1 & 28.95 & 75.28 \\
\hline 250 & 270.85 & 36 & 86.71 \\
\hline
\end{tabular}

ND= Not Detected (below $1^{\text {st }}$ analytical standard) 

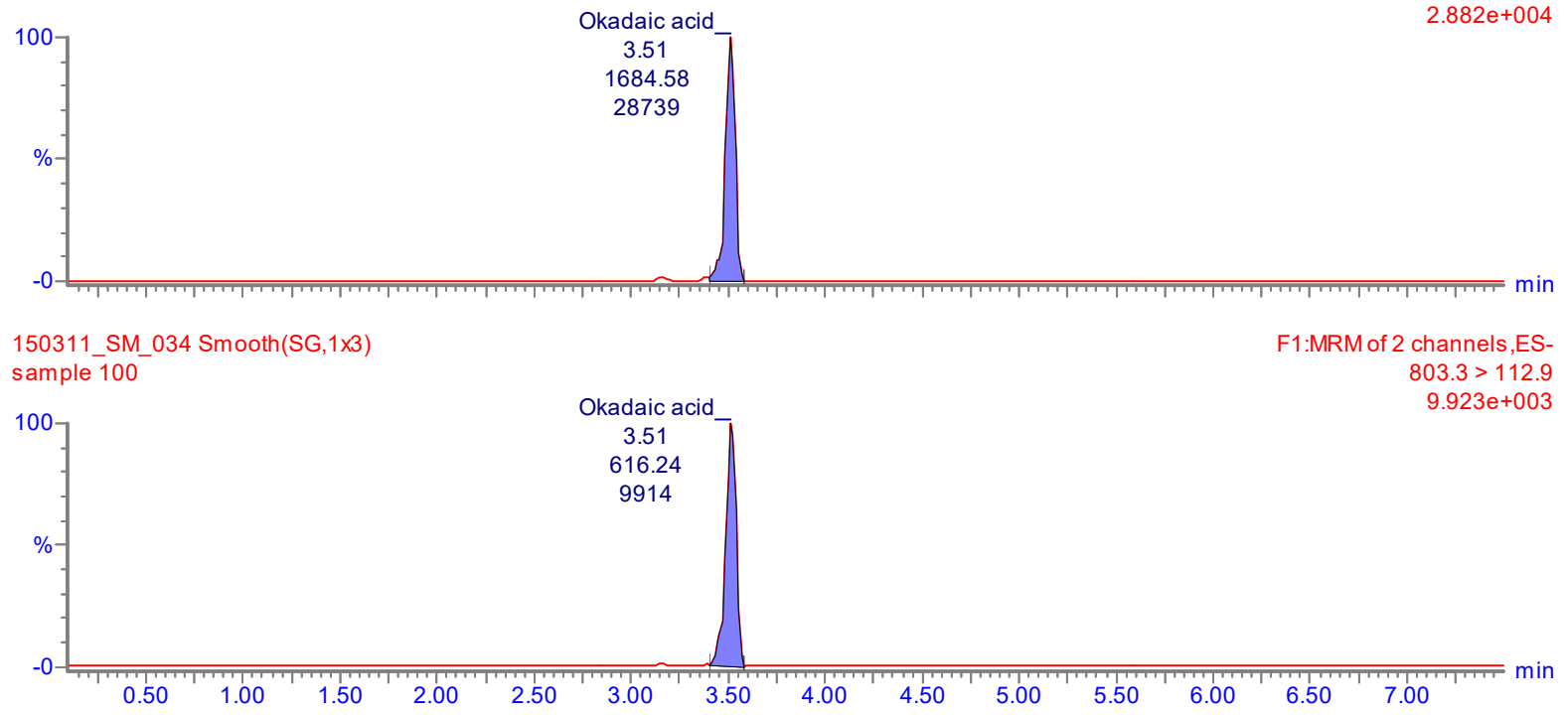

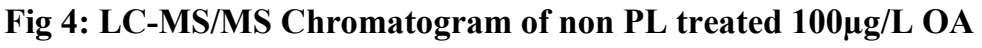

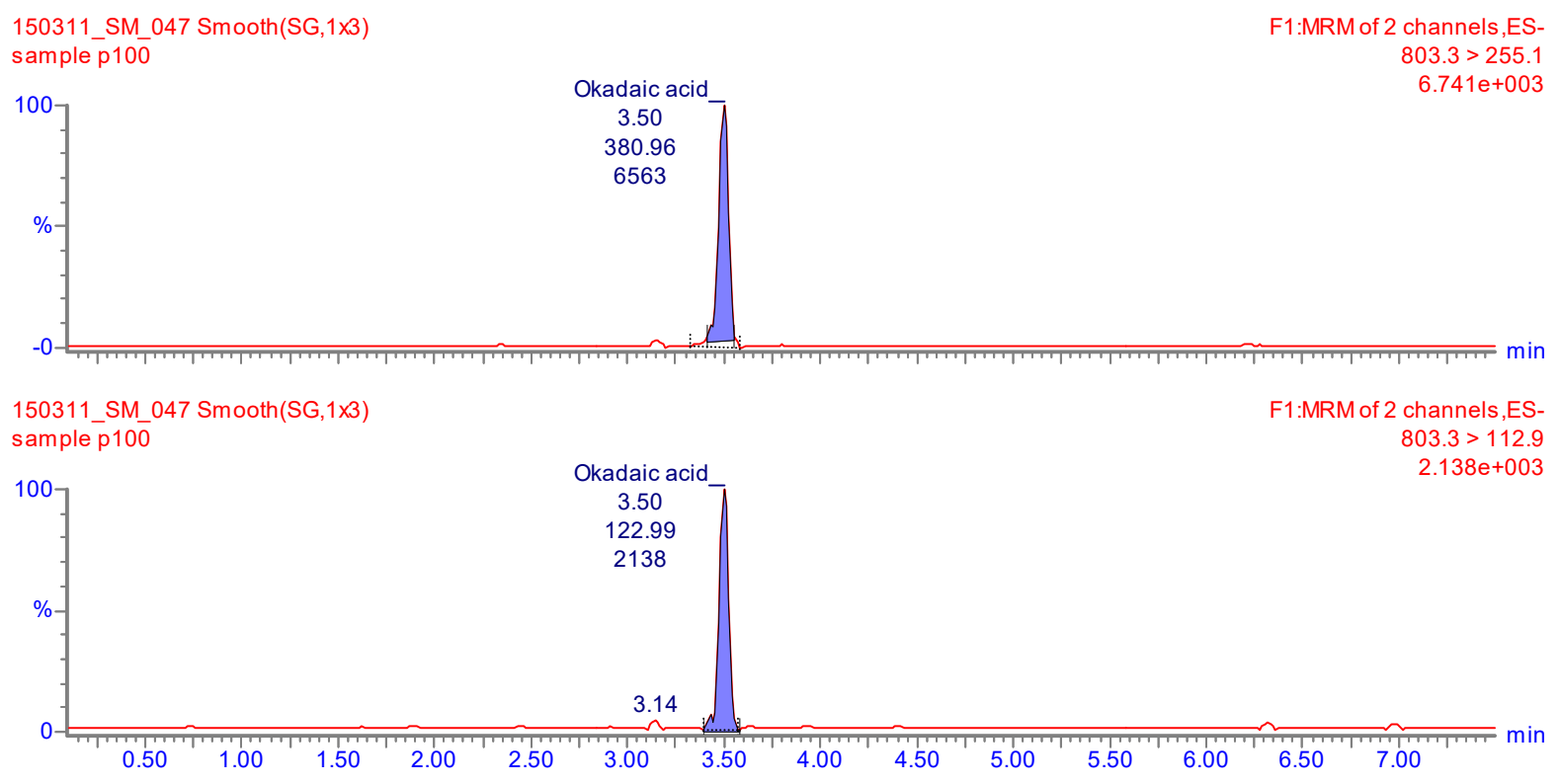

Fig 5: LC-MS/MS Chromatogram of PL treated 100 $\mu \mathrm{g} / \mathrm{L}$ OA

\section{Discussion}

Given the economic losses incurred by the aquaculture industry it is prudent to investigate remedial and preventative processes to mitigate these loses. To this end, the efficacy of PL to reduce the toxicity of OA to Daphnia pulex was investigated. The use of PL effectively reduced Cryptosporidium parvum by $4 \log ^{10}$ orders and subsequent ecotoxicological assessments revealed that PL could be safely used for water decontamination applications, which highlights the importance of conducting tandem environmental testing. In terms of in situ water disinfection studies for the fisheries industry, recent reports show that PL can be scaled up for treating contaminated water at wastewater treatment plant level (Garvey and Rowan, 2015; Rowan et al., 2016). 
A high UV dose of $12.98 \mu \mathrm{J} / \mathrm{cm}^{2}$ was used in this study for investigating efficacy of PL for reducing okadaic acid as this dosage was reported to be effective against recalcitrant bacterial endospores (Garvey and Rowan, 2015), which are more resistant to UV irradiation compared to that of vegetative bacteria and other microorganisms. Selection of this UV dosage was also based on related findings of Farrell et al. (2011), where these researchers reported that irreversible destruction of pathogenic yeast occurred at this upper PL-intensity due to inflicting a multi-hit destructive processes at the cellular and molecular level. This is in marked contrast to conventional UV delivery approaches that rely on causing damage to genetic material where treated microorganisms are often capable of mounting an adaptive protective effect (Rowan et al., 2016). While this study demonstrated potential for reducing the toxicity of algal toxin to freshwater crustacean Daphnia pulex, future intensive studies are merited to explore the efficacy of PL technology for treating a broad range of algae and phytoplankton toxins as this would have implications in terms of disinfection potential.

As the test performed is an adaptation of the classical ISO method necessitated by the need for reduced volumes due to the cost of purified OA, correlation between the two test formats was established using the ISO prescribed reference chemical $\mathrm{K}_{2} \mathrm{Cr}_{2} \mathrm{O}_{7}$. As indicated in Figure 3, a Pearson correlation coefficient of 0.9883 was observed with a confidence interval of $0.9344-0.9980$.

This study demonstrates that the use of PL resulted in more than a 15-fold reduction in the toxicity of OA to Daphnia pulex $\left(24 \mathrm{hr} \mathrm{EC}_{50}\right.$ for untreated OA was $1.68 \mu \mathrm{g} / \mathrm{L}$ and for PL treated OA was $25.87 \mu \mathrm{g} / \mathrm{L}$ ). A concomitant reduction of $86 \%$ at $250 \mu \mathrm{g} / \mathrm{L}$, reducing to $75 \%$ and $65 \%$ at $100 \mu \mathrm{g} / \mathrm{L}$ and $50 \mu \mathrm{g} / \mathrm{L}$ respectively was confirmed by LC-MS/MS analysis.

Although the LC-MS/MS analysis included for DTX-1 and none was observed, further studies are warranted to elucidate the derivatives of PL treated OA. This study demonstrates the novel application of PL to significantly reduce the toxicity of OA to Daphnia pulex. Potentially, this non-chemical method could be expanded to treat a broad range of algal toxins.

\section{References:}

Baumann, J., Sakka, Y., Bertrand, C., Köser, J., \& Filser, J. (2014). Adaptation of the Daphnia sp. acute toxicity test: miniaturization and prolongation for the testing of nanomaterials. Environmental Science and Pollution Research International, 21(3), 2201-13. doi: 10.1007/s11356-013-2094-y.

Ben-Gigirey, B., Rodríguez-Velasco, M., Villar-González, A. and Botana, L. (2007). Influence of the sample toxic profile on the suitability of a high performance liquid chromatography method for official paralytic shellfish toxins control. Journal of Chromatography A, 1140(1-2), pp.78-87.

Bord Iascaigh Mhara, Irish Sea Fisheries Board, (2015). 2014 BIM Annual Aquaculture Survey. [online] Available at: http://www.bim.ie/media/bim/content/publications/BIM\%20Aquaculture\%20Survey\%202014.pdf [Accessed 25 Jun. 2015].

FEAP, (2015). European Aquaculture Production Report 2005-2015.

FAO, 2016. The State of Word Fisheries and Aquaculture 2016, Rome, Italy.

Farrell, H.P., Hayes, J., Laffey, J.G., Rowan, N.J. (2011). Studies on the relationship between pulsed UV light and the simultaneous occurrence of molecular and cellular damage in clinically-relevant Candida albicans. Journal of Microbiological Methods 84: 317-326. 
FSAI.ie, (2015). Health Standards | Aquaculture | Food Legislation | Legislation | The Food Safety Authority of Ireland. [online] Available at: https://www.fsai.ie/legislation/food_legislation/aquaculture/health_standards.html [Accessed 25 Jun. 2015].

Fux E, Bire R, Hess P (2009) Comparative accumulation and composition of lipophilic marine biotoxins in passive samplers and in mussels (M. edulis) on the West Coast of Ireland. Harmful Algae 8:523-537

Fux E, Smith JL, Tong M, Guzman L, Anderson DM (2011) Toxin profiles of five geographical isolates of Dinophysis spp. From North and South America. Toxicon 57:275-287

Garvey, M.,Stocca, A., Rowan, N. (2016). Use of a real-time PCR assay to assess the effect of pulsed light inactivation on bacterial cell membranes and associated cell viability. Water Environ Res., 88(2): $168-174$.

Garvey, M., Hayes, J., Clifford, E., Rowan, N. (2015) Ecotoxicological assessment of pulsed ultraviolet light-treated water containing microbial species Cryptosporidium parvum using a microbiotest battery. Water and Environment Journal. (29) 27-35, doi: 10.1111/wej.12073

Garvey, M., Stocca, A., Rowan, N.J (2014). Development of a combined in vitro cell culturequantitative PCR assay for evaluating the disinfection performance of pulsed light for treating the waterborne enteroparasite Giardia lamblia. Experimental Parasitology. 144(1):6-13. PMID 24929148

Garvey, M., Farrell, H, Cormican M, Rowan N J. (2010). Investigations of the relationship between use of in vitro cell culture-quantitative PCR and a mouse-based bioassay for evaluating critical factors affecting the disinfection performance of pulsed UV light for treating Cryptosporidium parvum oocyts in saline. Journal of Microbiological Methods. 80: 267-273.

Gerssen A, Mulder PPJ, de Boer J (2011) Screening of lipophilic marine toxins in shellfish and algae: development of a library using liquid chromatography coupled to orbitrap mass spectrometry. Anal Chim Acta 685:176-185.

Hayes, J., Kirf, D., Garvey, M., \& Rowan, N. (2013). Disinfection and toxicological assessments of pulsed UV and pulsed-plasma gas-discharge treated-water containing the waterborne protozoan enteroparasite Cryptosporidium parvum. Journal of Microbiological Methods, 94(3), 325-37, doi: 10.1016/j.mimet.2013.07.012.

International Organisation for Standardisation. International Standard ISO 6341: 2012. Water Quality - Determination of the inhibition of the mobility of Daphnia magna Straus (Cladocera, Crustacea) Acute toxicity test. (2012).

Lilius, H., Hästbacka, T., \& Isomaa, B. (2005). Short communication: a comparison of the toxicity of 30 reference chemicals to Daphnia magna and Daphnia pulex. Environmental Toxicology and Chemistry, 14(2), 2085-2088, doi: 10.1002/etc.5620141211.

Luppis, A., Katikou, P., Georgantelis D, Badeka A, \& Kontominas M. (2011). Effect of ozonation and $\gamma$-irradiation on post-harvest decontamination of mussels (Mytillus galloprovincialis) containing diarrhetic shellfish toxins. Food Additives \& Contaminants: Part A, 28(12). 
Kumagai, M., Yanagai, T., Murata, M., Yasumoto, T., Kat, M., Lassus, P. and Rodriguez-Vazquez, J. (1986). Okadaic Acid as the Causative Toxin of Diarrhetic Shellfish Poisoning in Europe. Agricultural and Biological Chemistry, 50(11), pp.2853-2857, doi: 10.1080/00021369.1986.10867817

Naughton, J., Tiedeken, E.J., Stout, J., Rowan, N.J. 2017. Pulsed light inactivation of the bumble bee Trypanosome parasite Crithidia bombi. Journal of Apiculture Research, 56 (2), 144-154.

OECD (2004), Test No. 202: Daphnia sp. Acute Immobilisation Test, OECD Publishing, Paris. http://dx.doi.org/10.1787/9789264069947-en

Prego-Faraldo, M. V., Valdiglesias, V., Méndez, J., \& Eirín-López, J. M. (2013). Okadaic acid meet and greet: an insight into detection methods, response strategies and genotoxic effects in marine invertebrates. Marine Drugs, 11(8), 2829-45, doi: 10.3390/md11082829.

Rowan N.J. (2011). Defining Established and Emerging Microbial Risks in the Aquatic Environment: Current Knowledge, Implications, and Outlooks, International

Journal of Microbiology, vol. 2011, Article ID 462832, 15 pages, 2011. doi:10.1155/2011/462832

Rowan, N., Valdramidis, V.P., Gomez-Lopez, V.M. (2016). A review of quantitative methods to describe efficacy of pulsed light inactivation data that embraces the occurrence of viable non culturable microorganisms. Trends in Food Science and Technology 44(1),79-92.

Twiner M.J., Rehmann N., Hess P., Doucette G.J. (2008). Azaspiracid shellfish poisoning: a review on the chemistry, ecology, and toxicology with an emphasis on human health impacts

Mar. Drugs, 6 (2) (2008), pp. 39-72.

Vernoux, J.P., Le Baut, C., Masselin, O., Marais, C., Baron, B., Choumiloff, R., Pronieewski, F., Nizard, G., Bohec, M. (1993). The use of Daphnia magna for detection of okadaic acid in mussel extracts. Food Additives and Contaminants, 10(5), 603-608, doi: 10.1080/02652039309374184.

Yasumoto, T., Oshima, Y. and Yamaguchi, M., 1978. Occurrence of a New Type of Shellfish Poisoning in Tohoku District. Bulletin of the Japanese Society of Scientific Fisheries, 44(11), pp. 1249-1255. 